\title{
Six new recombinant inbred populations for the study of quantitative traits in Arabidopsis thaliana
}

\author{
Carmel M. O'Neill · Colin Morgan · Jane Kirby · Hendrik Tschoep · \\ Polo Xiaoyi Deng • Mahon Brennan • Ulises Rosas • Fiona Fraser • \\ Caroline Hall $\cdot$ Samantha Gill $\cdot$ Ian Bancroft
}

Published online: 27 March 2008

(C) Springer-Verlag 2008

\section{Erratum to: Theor Appl Genet (2008) 116:623-634 DOI 10.1007/s00122-007-0696-9}

The locus genotyping file used for the analysis of the NG population reported in the manuscript contained the incorrect assignment of maternal and paternal alleles. Consequently:

The proportion of maternal alleles in this population (Table 3) should be $54.4 \%$, not $45.6 \%$.

The parental assignment of genome representation for this population (Fig. 1) shows male alleles expressed as a percentage of male and female alleles combined, not female alleles expressed as a percentage of male and female alleles combined. Nok-3 alleles are thus over-represented in regions of chromosomes 1 and 2, and under-represented in a region of chromosome 4 .

For each of the three flowering time QTL identified in this population (Fig. 2; Table 4), the increasing allele is from Nok-3, not Ga-0.

The correct versions are given here.

The online version of the original article can be found under doi:10.1007/s00122-007-0696-9.

C. M. O’Neill · C. Morgan · J. Kirby · P. X. Deng ·

U. Rosas · F. Fraser · C. Hall · S. Gill I. Bancroft ( $\square)$

John Innes Centre, Norwich Research Park,

Colney, Norwich NR4 7UH, England

e-mail: ian.bancroft@bbsrc.ac.uk

H. Tschoep

Max-Planck-Institute for Molecular Plant Physiology,

14476 Potsdam-Golm, Germany

\section{Brennan}

Monsanto International, Rue des Vignerons 1A,

1110 Morges, Switzerland 
Table 3 Genetic analysis of the recombinant populations at the F8 generation

\begin{tabular}{lcllllll}
\hline Population & Total Mb & Total cM & $\begin{array}{l}\text { Average distance } \\
\text { between markers (cM) }\end{array}$ & $\begin{array}{l}\text { Numbers of markers } \\
\text { used in the maps }\end{array}$ & kb/cM & $\begin{array}{l}\text { Residual } \\
\text { heterozygosity (\%) }\end{array}$ & $\begin{array}{l}\text { Maternal alleles in } \\
\text { the populations (\%) }\end{array}$ \\
\hline NG & 114 & 448 & 7.7 & 58 & 255 & 1.0 & 54.4 \\
TJ & 108 & 386 & 7.3 & 53 & 280 & 0.8 & 49.2 \\
CA & 107 & 453 & 9.6 & 47 & 236 & 0.65 & 40.5 \\
KB & 104 & 351 & 6.8 & 52 & 296 & 1.0 & 41.4 \\
SG & 97 & 297 & 6.2 & 48 & 326 & 0.8 & 43.9 \\
WC & 112 & 470 & 8.2 & 57 & 238 & 0.6 & 52.8 \\
\hline
\end{tabular}

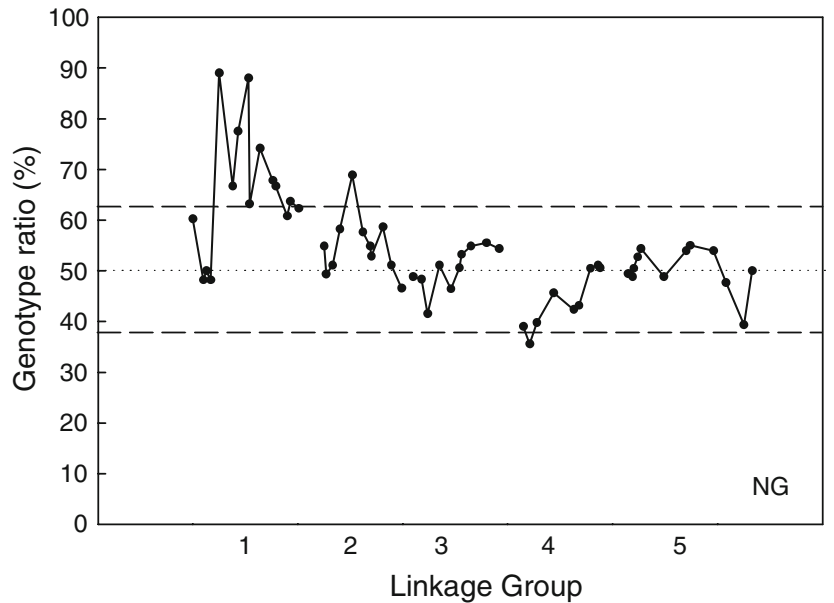

Fig. 1 Allele segregation ratios for the six populations. The female alleles are expressed as a percentage of the male and female alleles combined. The significance threshold $P<0.001$ (i.e. between 38 and $62 \%)$ is indicated by the horizontal dashed lines
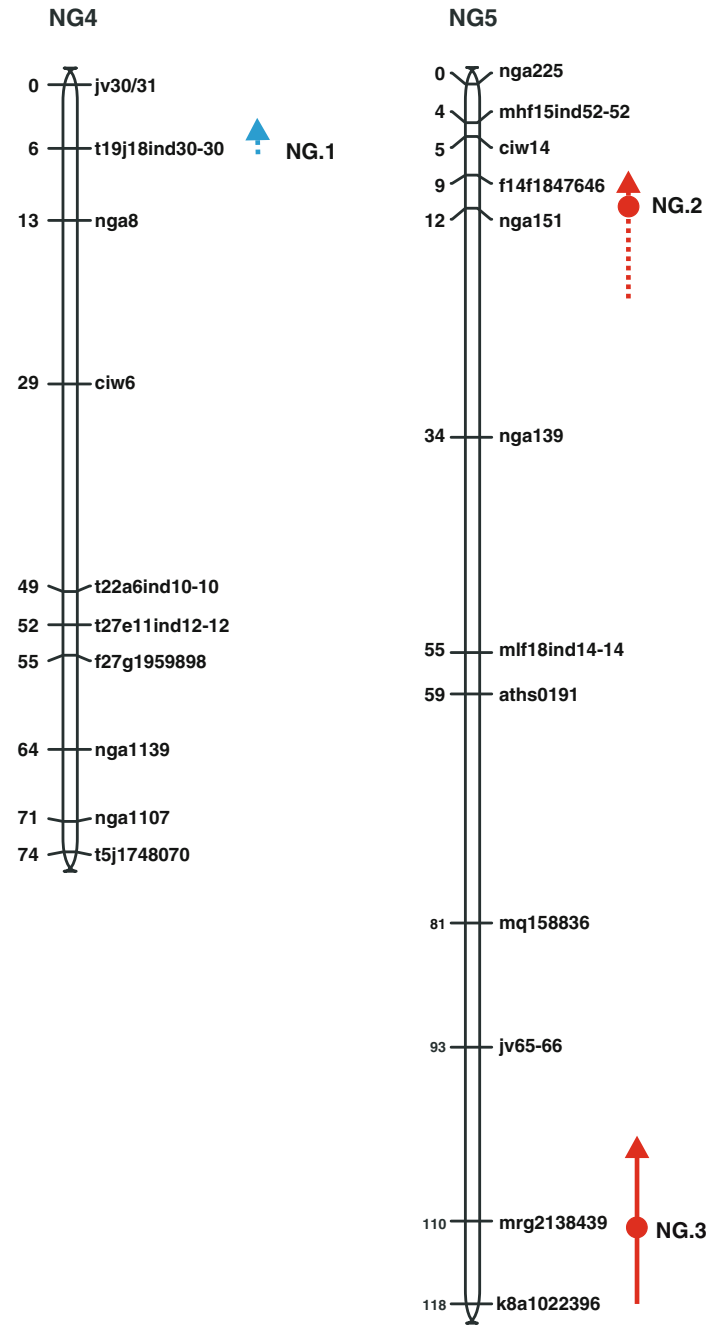

Fig. 2 QTL for flowering time for 6 RIL Arabidopsis populations. The position of the QTL are represented as 2 LOD intervals where sufficiently large, solid lines, otherwise the 5\% significance LOD threshold is used, dashed lines. The position of peak LOD scores are indicated by closed circles. QTL detected by interval mapping are indicated in red, while QTL detected only by CIM mapping are indicated in blue. Upward arrows indicate the maternal parent as the source of the increasing allele, downward arrows indicate the paternal parent as the source of the increasing allele 
Table 4 QTL affecting flowering time in the six populations and heritability in the individual populations

\begin{tabular}{|c|c|c|c|c|c|c|c|c|}
\hline \multirow[t]{2}{*}{ Population } & \multirow[t]{2}{*}{ Heritability $\left(h_{\mathrm{b}}^{2}\right)$} & \multicolumn{7}{|c|}{ QTL analysis } \\
\hline & & QTL & Chr & LOD max & $\begin{array}{l}\text { QTL position } \\
(\mathrm{cM})\end{array}$ & $\begin{array}{l}\text { Peak max } \\
(\mathrm{cM})\end{array}$ & $\begin{array}{l}\text { Variation } \\
\text { explained (\%) }\end{array}$ & $\begin{array}{l}\text { Increasing } \\
\text { allele }\end{array}$ \\
\hline $\mathrm{KB}^{\mathrm{a}}$ & 0.69 & KB.1 & $\mathrm{C} 2$ & 13 & $26.5-34$ & 30.7 & 58 & Kondara \\
\hline \multirow[t]{3}{*}{$\mathrm{NG}^{\mathrm{b}}$} & 0.65 & NG. $1^{\mathrm{c}}$ & $\mathrm{C} 4$ & 2.5 & 6 & 6 & 10 & Nok-3 \\
\hline & & NG.2 & $\mathrm{C} 5$ & 4 & $7.7-20$ & 11 & 19 & Nok-3 \\
\hline & & NG.3 & $\mathrm{C} 5$ & 4.7 & $101-117$ & 110 & 22 & Nok-3 \\
\hline \multirow[t]{3}{*}{$\mathrm{TJ}^{\mathrm{a}}$} & 0.63 & TJ. $1^{\mathrm{c}}$ & $\mathrm{C} 4$ & 2.9 & $0-2$ & 0 & 9 & Ts-5 \\
\hline & & TJ.2 & $\mathrm{C} 5$ & 3.1 & $13.7-26$ & 19.7 & 18 & Ts-5 \\
\hline & & TJ.3 & $\mathrm{C} 5$ & 7.4 & $74-97$ & 89.9 & 37 & $240 \# 14$ \\
\hline $\mathrm{CA}^{\mathrm{b}}$ & 0.2 & CA. 1 & $\mathrm{C} 4$ & 7.4 & $0.5-14$ & 4 & 38 & Ag- 0 \\
\hline \multirow[t]{5}{*}{$\mathrm{SG}^{\mathrm{a}}$} & 0.82 & SG.1 & $\mathrm{C} 1$ & 3.8 & $68-74.5$ & 74.5 & 14 & Gy-0 \\
\hline & & SG. 2 & $\mathrm{C} 4$ & 3.4 & $0-6$ & 1.4 & 16 & Sorbo \\
\hline & & SG. $3^{\mathrm{c}}$ & $\mathrm{C} 4$ & 3.8 & $16-38$ & 30.5 & 15 & Sorbo \\
\hline & & SG.4 & $\mathrm{C} 5$ & 4.3 & $10-32$ & 21.3 & 20 & Gy-0 \\
\hline & & SG. 5 & $\mathrm{C} 5$ & 5.1 & $45.6-63.8$ & 63.8 & 23 & Gy-0 \\
\hline \multirow[t]{2}{*}{$\mathrm{WC}^{\mathrm{b}}$} & 0.6 & WC.1 & $\mathrm{C} 5$ & 8.9 & 93-103 & 96.8 & 37 & Wt-5 \\
\hline & & WC.2 & $\mathrm{C} 5$ & 10.2 & 107-end & 112.2 & 41 & Wt-5 \\
\hline
\end{tabular}

a Population grown in a glasshouse

${ }^{b}$ Population grown in a controlled environment room

${ }^{c}$ QTL detected only in the MQM analysis 